\title{
Bone Mineral Densities and Mechanical Properties of Retrieved Femoral Bone Samples in relation to Bone Mineral Densities Measured in the Respective Patients
}

\author{
Yvonne Haba, ${ }^{1}$ Ralf Skripitz, ${ }^{1}$ Tobias Lindner, ${ }^{1}$ Martin Köckerling, ${ }^{2}$ Andreas Fritsche, ${ }^{1}$ \\ Wolfram Mittelmeier, ${ }^{1}$ and Rainer Bader ${ }^{1}$ \\ ${ }^{1}$ Biomechanics and Implant Technology Research Laboratory, Department of Orthopaedics, University Medicine Rostock, \\ 18057 Rostock, Germany \\ ${ }^{2}$ Inorganic Solid State Chemistry Group, Institute of Chemistry, University of Rostock, 18057 Rostock, Germany
}

Correspondence should be addressed to Rainer Bader, rainer.bader@med.uni-rostock.de

Received 9 August 2012; Accepted 18 September 2012

Academic Editors: D. H. Lee, C. C. Niu, and J. B. Renner

Copyright ( 2012 Yvonne Haba et al. This is an open access article distributed under the Creative Commons Attribution License, which permits unrestricted use, distribution, and reproduction in any medium, provided the original work is properly cited.

\begin{abstract}
The bone mineral density (BMD) of retrieved cancellous bone samples is compared to the BMD measured in vivo in the respective osteoarthritic patients. Furthermore, mechanical properties, in terms of structural modulus $\left(E_{s}\right)$ and ultimate compression strength $\left(\sigma_{\max }\right)$ of the bone samples, are correlated to BMD data. Human femoral heads were retrieved from 13 osteoarthritic patients undergoing total hip replacement. Subsequently, the BMD of each bone sample was analysed using dual energy X-ray absorptiometry (DXA) as well as ashing. Furthermore, BMDs of the proximal femur were analysed preoperatively in the respective patients by DXA. BMDs of the femoral neck and head showed a wide variation, from $1016 \pm 166 \mathrm{mg} / \mathrm{cm}^{2}$ to $1376 \pm 404 \mathrm{mg} / \mathrm{cm}^{2}$. BMDs of the bone samples measured by DXA and ashing yielded values of $315 \pm 199 \mathrm{mg} / \mathrm{cm}^{2}$ and $347 \pm 113 \mathrm{mg} / \mathrm{cm}^{3}$, respectively. $E_{s}$ and $\sigma_{\max }$ amounted to $232 \pm 151 \mathrm{~N} / \mathrm{mm}^{2}$ and $6.4 \pm 3.7 \mathrm{~N} / \mathrm{mm}^{2}$. Significant correlation was found between the DXA and ashing data on the bone samples and the DXA data from the patients at the femoral head $\left(r=0.85\right.$ and 0.79 , resp.). E $E_{s}$ correlated significantly with BMD in the patients and bone samples as well as the ashing data $(r=0.79, r=0.82$, and $r=0.8$, resp.).
\end{abstract}

\section{Introduction}

Dual energy X-ray absorptiometry (DXA), used to evaluate bone quality and predict the risk of bone fracture [1], represents a functional diagnostic tool to determine the mineral density of human femoral bone samples. Bone quality and fracture risk depend on geometric parameters and properties of the material [2]. In order to clarify the relationship between mechanical properties and bone mineral density (BMD), various experimental studies with different measurement techniques have been carried out [3-6]. Radiographic analyses such as DXA or quantitativecomputed tomography (QCT) are standard diagnostic tools for assessment of BMD in patients. Ashing has also been used experimentally for in vitro determination of BMD [7-9]. However, a comparison of mechanical properties as well as the BMD of retrieved bone samples measured by ashing and DXA with BMD analysis of the respective patients as measured by DXA has not as yet been performed.

To determine the mechanical properties, for example, the structural modulus $\left(E_{s}\right)$ or ultimate compression strength $\left(\sigma_{\max }\right)$, of human cancellous bone, uniaxial compression tests have been used in most cases [4, 9-11]. Ebbesen et al. [12] analysed the relationship between $\sigma_{\max }$, DXA, QCT samples, and ashing samples of the lumbar vertebral body in vitro using bone samples. Fazzalari et al. [13] also compared BMD and mechanical properties of human osteoarthritic femoral cancellous bone samples in vitro.

The aim of the present study is to compare the in vivo measured BMD of the femur, that is, femoral head and neck, in osteoarthritic patients with the BMD of cylindrical cancellous bone samples retrieved from the respective patients after undergoing total hip replacement and intraoperative removal of the femoral head. Furthermore, mechanical 
properties, that is, structural modulus $\left(E_{s}\right)$ and ultimate compression strength $\left(\sigma_{\max }\right)$, of the bone samples were compared with their BMD as measured by DXA and ashing as well as the BMD measured in vivo in patients by DXA.

\section{Materials and Methods}

2.1. Sample Preparation. Human femoral heads were retrieved from 13 female donors aged between 53 and 76 years undergoing primary total hip replacement and stored postoperatively for a maximum of 24 hours at +6 to $8^{\circ} \mathrm{C}$. Subsequently, the femoral heads were frozen in small sealed containers at $-20^{\circ} \mathrm{C}$ [14]. The specimens were moved 12 hours before testing to the refrigerator $\left(+6^{\circ}\right.$ to $\left.+8^{\circ} \mathrm{C}\right)$ and were frozen at $-20^{\circ} \mathrm{C}$ between the different tests. The DXA investigations were performed first, followed by analysis of the mechanical properties and finally by ashing the bone samples. All tests were conducted at room temperature. The tests were approved by the local Ethical Committee of the University of Rostock (A 2009 38).

According to DIN 50106 [15], cylindrical bone samples from the centre of the femoral head with a height to diameter ratio between 1 and 2 were used in order to avoid buckling of the test samples during the compression tests. A cylindrical sample approximately $30 \mathrm{~mm}$ in length and $12 \mathrm{~mm}$ in diameter was cut from each femoral head using a diamond hollow drill (Günther Diamantwerkzeuge, Idar-Oberstein, Germany). The drill was positioned on the femoral head at the base of the ligamentum capitis femoris aligned with the femoral neck axis. The endplates of the bone cylinders were prepared in a tube-like template [10] to assure parallel alignment of the cancellous bone cylinders and an exact length of $15 \mathrm{~mm}$.

2.2. DXA. BMD analysis of each patient was performed using the standardized region of interest (ROI) of the femoral neck as well as an adaptable ROI of the femoral head referencing the geometry of the cancellous bone samples. Moreover, the BMD measurements on the cylindrical samples were conducted with a DXA device (Lunar Prodigy, General Electric (GE) Healthcare, Munich, Germany) using the research option (electrical potential of $76 \mathrm{kV}$ and electrical current of $0.15 \mathrm{~mA}$ ). Calibration control of the Lunar Prodigy device was performed daily based on a cuboid calibration phantom $(200 \times 130 \times 60 \mathrm{~mm})$ with three different BMD bone equivalent chambers with values of $0.5 \mathrm{~g} / \mathrm{cm}^{2}$, $1.0 \mathrm{~g} / \mathrm{cm}^{2}$, and $1.5 \mathrm{~g} / \mathrm{cm}^{2}$. The BMD was obtained by using the DXA software enCORE 2007 (version 11.40.004, General Electric (GE) Medical Systems, Madison, WI, USA). The preoperatively performed DXA of the patient was used to set a similar ROI position on the bone samples in the femoral head as shown in Figure 1. In order to avoid the overlap by the acetabulum while performing the DXA measurements, the ROI and real sample positions differed approximately $20 \mathrm{~mm}$ in the longitudinal axis. The $T$-score measured in the present study indicates the number of standard deviations above or below the mean for a healthy thirty-year-old normal population with the same gender and ethnicity as the patient. The $T$-score determination is usable in standardised patient measurements, but not applicable for in vitro bone samples. According to the criteria of the World Health Organization (WHO), normal $T$-scores range up to -1 . Osteopenia is defined as between -1 and -2.5 and osteoporosis as less than -2.5 .

2.3. Uniaxial Compression Test. The mechanical properties were derived from a uniaxial compression test assessing the structural modulus $\left(E_{s}\right)$ and the ultimate compression strength $\left(\sigma_{\max }\right)$. According to Hooke's law $(1), E_{s}$ provides a linear relationship between stress $(\sigma)$ and strain $(\varepsilon)$. Stress and strain data were calculated from the linear part of the load-displacement curve. The ultimate compression strength $\left(\sigma_{\max }\right)$ was reached at the maximum of the compression stress curve during the test. A universal testing machine (Z050, Zwick/Roell, Ulm, Germany) was used to apply axial compression loads to investigate the cylindrical cancellous bone samples. The test speed was set to $5 \mathrm{~mm} / \mathrm{min}$ [12] until a total displacement of $4 \mathrm{~mm}$ was reached:

$$
E_{s}=\frac{\sigma}{\varepsilon}
$$

2.4. Ashing. After compression testing the cylindrical bone samples were combusted in a tube furnace (Nabertherm, Lilienthal, Germany) at $800^{\circ} \mathrm{C}$ for $5 \mathrm{~h}$ [16]. The BMD was calculated as ash weight divided by the gross sample volume [17].

2.5. Statistical Analysis. The linear correlation coefficient $(r)$ between the different BMDs as well as their mechanical properties was determined by the Pearson correlation. The statistical analysis was determined with the SPSS, Version 20 (SPSS Inc., Chicago, IL, USA) software package. The significance level was set at $P<0.05$.

\section{Results}

In the present investigation we compared BMDs (DXA and ashing) and mechanical properties $\left(E_{s}\right.$ and $\left.\sigma_{\max }\right)$ of retrieved femoral bone samples to the preoperatively measured BMDs of the identical patients.

3.1. Bone Mineral Densities and Mechanical Properties of the Samples. The BMDs of the cancellous bone samples averaged $315 \pm 199 \mathrm{mg} / \mathrm{cm}^{2}$ as measured by DXA and $347 \pm$ $113 \mathrm{mg} / \mathrm{cm}^{3}$ measured by ashing. The mechanical properties of the bone samples were characterized by a structural modulus $\left(E_{s}\right)$ of $232 \pm 151 \mathrm{~N} / \mathrm{mm}^{2}$ and ultimate compression strength $\left(\sigma_{\max }\right)$ of $6.4 \pm 3.7 \mathrm{~N} / \mathrm{mm}^{2}$ (Table 1$)$. The BMDs and mechanical parameters showed high standard deviations (Table 1).

3.2. Bone Mineral Densities of the Patients. The T-score of the patient's femoral neck averaged $0.31 \pm 1.38$ (range -1.8 to +2.6). This encompassed a broad distribution of bone densities (from normal to osteopenia bone). The results of the bone mineral densities of the patients presented as mean value \pm standard deviation, minimum and maximum are 


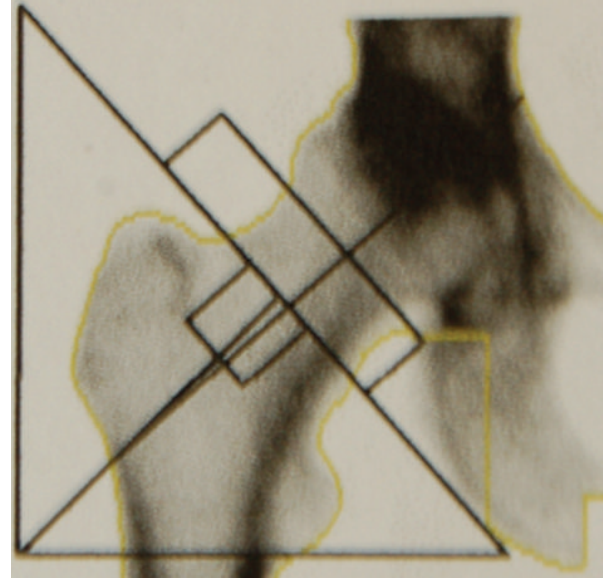

(a)

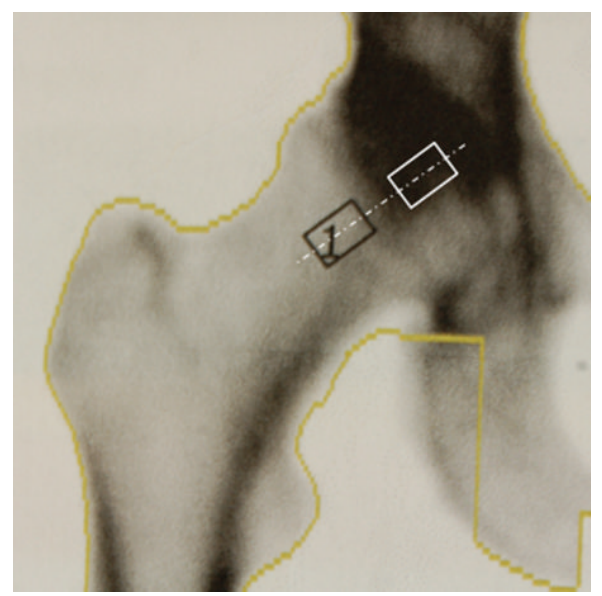

(b)

FIGURE 1: Standard BMD measurement of the patient femoral neck using DXA (a). Bone sample position for in vivo measurement of the bone sample (black) and the position of the retrieved cancellous bone sample (white) (b).

TABLE 1: Mean value \pm standard deviation (SD), minimum and maximum of bone mineral densities and mechanical properties of 13 bone samples.

\begin{tabular}{lcccccc}
\hline & $\begin{array}{c}\text { DXA BMD femoral neck } \\
{\left[\mathrm{mg} / \mathrm{cm}^{2}\right]}\end{array}$ & $\begin{array}{c}\text { DXA BMD femoral head } \\
{\left[\mathrm{mg} / \mathrm{cm}^{2}\right]}\end{array}$ & $\begin{array}{c}\text { DXA BMD } \\
{\left[\mathrm{mg} / \mathrm{cm}^{2}\right]}\end{array}$ & $\begin{array}{c}\text { Ashing BMD } \\
{\left[\mathrm{mg} / \mathrm{cm}^{3}\right]}\end{array}$ & $\begin{array}{c}E_{s} \\
{\left[\mathrm{~N} / \mathrm{mm}^{2}\right]}\end{array}$ & $\begin{array}{c}\sigma_{\text {max }} \\
{\left[\mathrm{N} / \mathrm{mm}^{2}\right]}\end{array}$ \\
& Patient measurements & Patient measurements & Bone samples & Bone samples & Bone samples & Bone samples \\
\hline Mean $\pm \mathrm{SD}$ & $1016 \pm 166$ & $1376 \pm 404$ & $315 \pm 199$ & $347 \pm 113$ & $232 \pm 151$ & $6.4 \pm 3.7$ \\
Min & 768 & 823 & 97 & 199 & 51 & 1.9 \\
Max & 1289 & 2081 & 734 & 567 & 624 & 13.5 \\
\hline
\end{tabular}

given in Table 1. Therefore, patient DXA measurements of the femoral neck and head showed significant differences and high standard deviations, that is, \pm 166 and $\pm 404 \mathrm{mg} / \mathrm{cm}^{2}$, respectively (Table 1 ).

\subsection{Correlation of Bone Mineral Densities with Mechanical} Properties. A significant correlation exists between the DXA data on the bone samples derived from the centre of the femoral head and the DXA data from the patient measurements at the femoral head $(r=0.85, P<0.01)$, whereas only a weak correlation was found between the DXA on the bone sample and the DXA on the patient measurements of the femoral neck, as shown in Table 2.

Additionally, the best significant linear correlation was observed between ashing and DXA BMD on the bone samples $(r=0.92, P<0.01)$. The structural modulus $\left(E_{s}\right)$ was also significant comparing DXA BMD femoral head (patient), bone sample, and ashing $(r=0.79, r=0.82$, and $r=0.8, P<0.01$ ) (Table 3 ).

The distribution and linear correlations of the BMDs versus $E_{s}$ are represented in Figures 2, 3, 4, and 5. Comparing the mechanical properties, DXA and ashing with the age of the patient revealed only low or no statistical correlations. Table 4 illustrates the results of our measurements in comparison to other experimental studies.

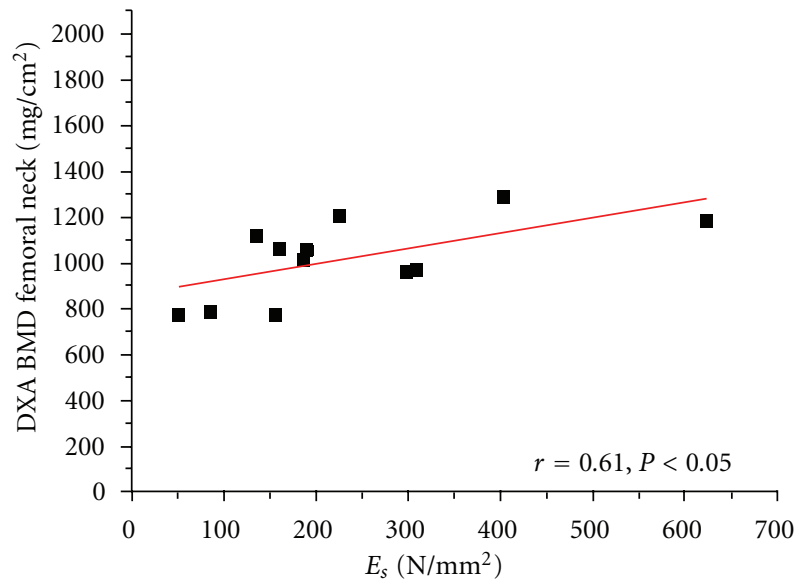

FIGURE 2: Linear correlation of structural modulus $\left(E_{s}\right)$ versus DXA $\mathrm{BMD}$ on femoral neck (standardised patient measurements).

\section{Discussion}

The aim of the present study is the comparison of mechanical properties and BMD measured at the femoral head and neck of osteoarthritic patients using ashing and DXA (in vitro and in vivo, resp.). For this, thirteen cancellous bone samples 
TABLE 2: Linear correlation between the BMD measured on each patient and BMD of the respective bone samples.

\begin{tabular}{|c|c|c|c|c|}
\hline & $\begin{array}{l}\text { DXA BMD femoral neck } \\
\text { Patient measurements }\end{array}$ & $\begin{array}{l}\text { DXA BMD femoral head } \\
\text { Patient measurements }\end{array}$ & $\begin{array}{c}\text { DXA BMD } \\
\text { Bone samples }\end{array}$ & $\begin{array}{l}\text { Ashing BMD } \\
\text { Bone samples }\end{array}$ \\
\hline DXA BMD femoral neck & 1 & $0.78^{* *}$ & $0.67 *$ & 0.49 \\
\hline DXA BMD femoral head & $0.78^{* *}$ & 1 & $0.85^{* *}$ & $0.79^{* *}$ \\
\hline DXA BMD & $0.67^{*}$ & $0.85^{* *}$ & 1 & $0.92 * *$ \\
\hline Ashing BMD & 0.49 & $0.79^{* *}$ & $0.92 * *$ & 1 \\
\hline
\end{tabular}

${ }^{*}$ Correlation is significant at the 0.05 level (2-tailed).

${ }^{* *}$ Correlation is significant at the 0.01 level (2-tailed).

TABLE 3: Linear correlation between BMD (DXA and ashing) and mechanical properties (structural modulus $\left(E_{s}\right)$ and ultimate compression strength $\left.\left(\sigma_{\max }\right)\right)$.

\begin{tabular}{lcccc}
\hline & DXA BMD femoral neck & DXA BMD femoral head & DXA BMD & Ashing BMD \\
& Patient measurements & Patient measurements & Bone samples & $0.82^{* *}$ \\
$E_{s}$ & $0.61^{*}$ & $0.79^{* *}$ & $0.61^{*}$ & $0.8^{* *}$ \\
$\sigma_{\max }$ & 0.36 & $0.56^{*}$ & $0.67^{*}$ \\
\hline
\end{tabular}

${ }^{*}$ Correlation is significant at the 0.05 level (2-tailed).

** Correlation is significant at the 0.01 level (2-tailed).

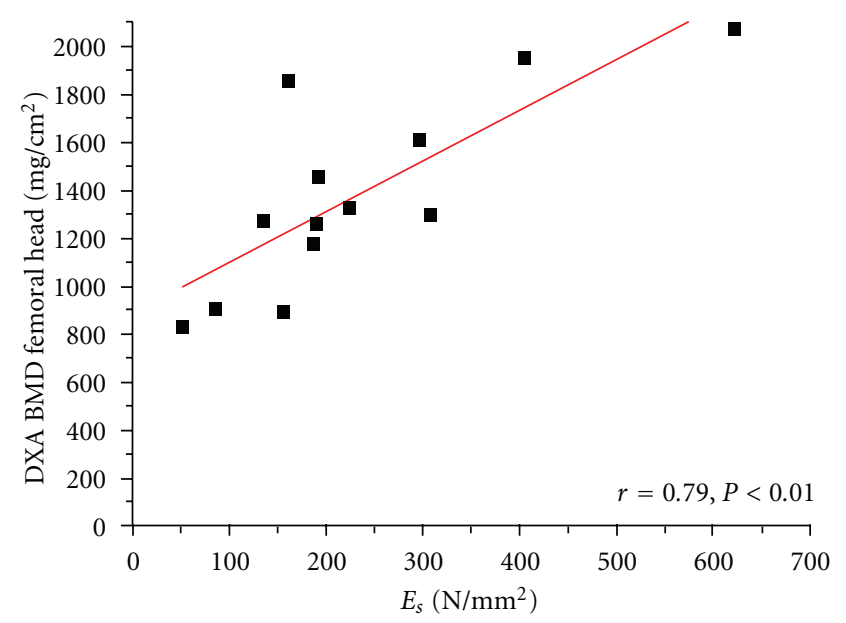

FIGURE 3: Linear correlation of structural modulus $\left(E_{s}\right)$ versus DXA $\mathrm{BMD}$ on femoral head (patient measurements).

from human femoral heads retrieved from female patients with hip osteoarthritis were investigated.

Bone samples of patients with osteoarthritis may be abnormal and show compositional changes, as investigated by Li and Aspden [17]. Therefore, we compared the mechanical and density properties of osteoarthritic bone with data on osteoporotic bone and bone samples from healthy donors (human femoral heads) post mortem [17]. Osteoarthritic bone samples revealed the greatest stiffness and apparent densities, and osteoporotic bone samples the lowest. Healthy and osteoporotic bone samples have shown similar linear regression relationships between mechanical and density properties [17].

Linear correlations have been observed between the mechanical properties and in vitro measured BMDs of bone samples, as well as the in vivo measured BMDs of the respective patients recorded by DXA. However, high

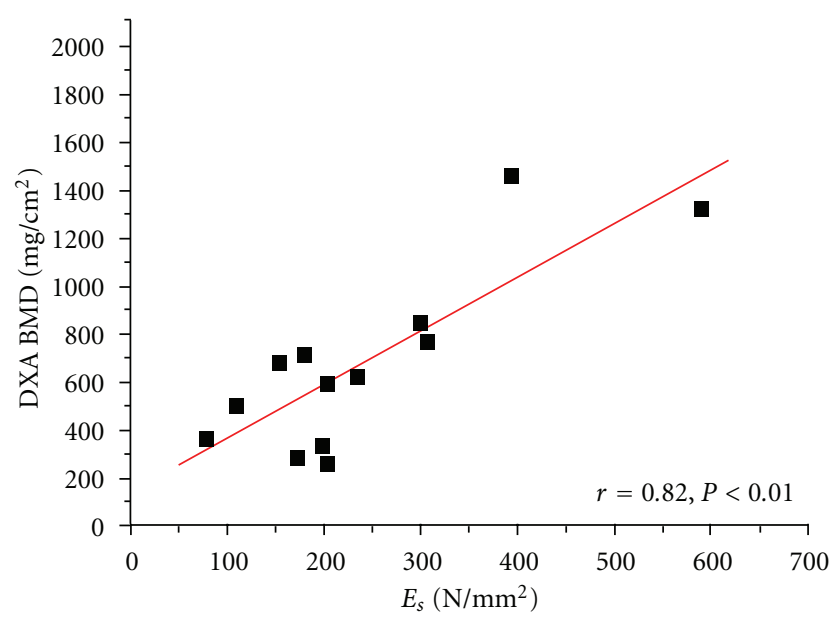

FIGURE 4: Linear correlation of structural modulus $\left(E_{s}\right)$ versus DXA BMD (on bone samples).

standard deviations within the different measurements were found (Tables 1 to 3 ).

In different experimental studies, bone mineral density and material parameters of human cancellous femoral bone samples that retrieved post mortem were analysed by other research groups $[10,11,18,22]$. Cody et al. [22] analysed male and female normal cancellous bone samples. They could demonstrate a DXA BMD at the femoral neck and greater trochanter of $650 \pm 130 \mathrm{mg} / \mathrm{cm}^{2}$ and $600 \pm 150 \mathrm{mg} / \mathrm{cm}^{2}$. In our present study, the patients' BMD amounted to $1016 \pm 166 \mathrm{mg} / \mathrm{cm}^{2}$ at the femoral neck and $1376 \pm 404 \mathrm{mg} / \mathrm{cm}^{2}$ at the femoral head. However, we only found BMD for the bone samples of about $315 \pm$ $199 \mathrm{mg} / \mathrm{cm}^{2}$. The reason for the lower BMD might be the measurement of osteoarthritic bone samples in contrast to other studies analysing samples derived from normal individuals [10, 22]. Uchiyama et al. [19] analysed bone samples 
TABLE 4: Results of BMD testing and mechanical properties of bone samples from the literature compared to own test data.

\begin{tabular}{|c|c|c|c|c|c|c|}
\hline & $\begin{array}{c}\text { DXA BMD femoral neck } \\
{\left[\mathrm{mg} / \mathrm{cm}^{2}\right]}\end{array}$ & $\begin{array}{l}\text { DXA BMD femoral head } \\
{\left[\mathrm{mg} / \mathrm{cm}^{2}\right]}\end{array}$ & $\begin{array}{l}\text { DXA BMD } \\
{\left[\mathrm{mg} / \mathrm{cm}^{2}\right]}\end{array}$ & $\begin{array}{c}\text { Ashing BMD } \\
{\left[\mathrm{mg} / \mathrm{cm}^{3}\right]}\end{array}$ & $\begin{array}{c}E_{s} \\
{\left[\mathrm{~N} / \mathrm{mm}^{2}\right]}\end{array}$ & $\begin{array}{c}\sigma_{\max } \\
{\left[\mathrm{N} / \mathrm{mm}^{2}\right]}\end{array}$ \\
\hline & Patient measurements & Patient measurements & Bone samples & Bone samples & Bone samples & Bone samples \\
\hline $\begin{array}{l}\text { Rohlmann et al., } 1980 \\
{[18]}\end{array}$ & & & & $399 \pm 130$ & $389 \pm 270$ & $7.4 \pm 4.0$ \\
\hline $\begin{array}{l}\text { Uchiyama et al., } 1999 \\
\text { [19] }\end{array}$ & & & $88 \pm 16$ & & $126 \pm 96.9$ & \\
\hline Au et al., 1998 [20] & $758 \pm 114$ & & & & & \\
\hline $\begin{array}{l}\text { Mazurkiewicz and } \\
\text { Topoliński, } 2009 \text { [21] }\end{array}$ & & & $289 \pm 69$ & & & $13.4 \pm 6.5$ \\
\hline Own data & $1016 \pm 166$ & $1376 \pm 404$ & $315 \pm 199$ & $347 \pm 113$ & $232 \pm 151$ & $6.4 \pm 3.7$ \\
\hline
\end{tabular}

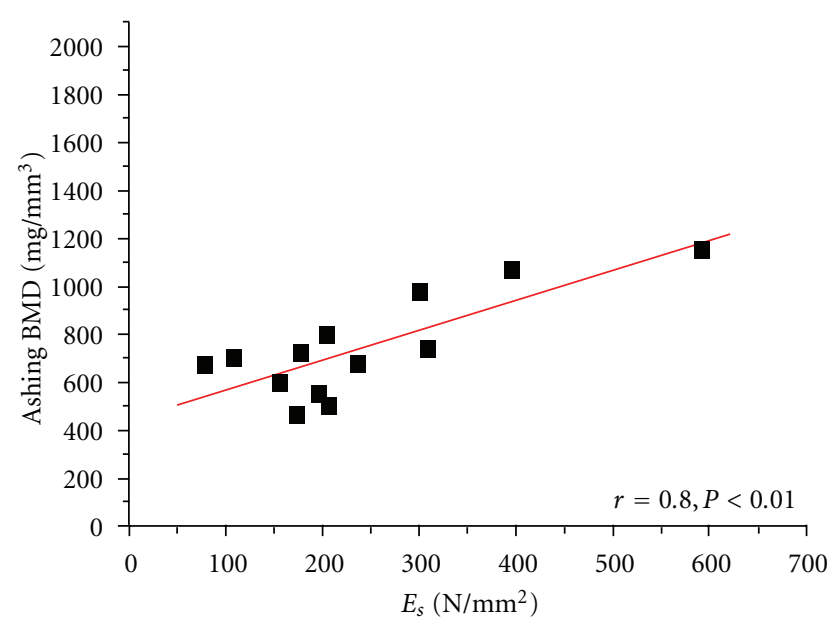

FIGURE 5: Linear correlation of structural modulus $\left(E_{s}\right)$ versus ashing BMD (on bone samples).

derived from lumbar vertebrae and harvested at autopsy of pancreatic cancer fatalities. The comparison between the elastic modulus and BMD showed a correlation of $r=$ $0.601, P<0.005$. Further in vitro examinations of cancellous femoral bone performed by Mazurkiewicz and Topoliński [21] showed good correlation between DXA BMD and ultimate compression strength of bone samples from patients with osteoporosis $(r=0.81)$ and hip osteoarthritis $(r=$ 0.71).

The mechanical properties of bone samples are often described with the Young's modulus [9-11]. Sierpowska et al. [11] found a high average Young's modulus of $624.4 \pm$ $213.9 \mathrm{~N} / \mathrm{mm}^{2}$ of cancellous bone (distal femur and proximal tibia) and an ultimate compression strength of $10.9 \pm$ $4.2 \mathrm{~N} / \mathrm{mm}^{2}$. By contrast, Steinhauser et al. [10] determined values of $385.7 \pm 189.4 \mathrm{~N} / \mathrm{mm}^{2}$ for the Young's modulus and $8.5 \pm 6.0 \mathrm{~N} / \mathrm{mm}^{2}$ for ultimate compression strength. Average values of $389 \pm 270 \mathrm{~N} / \mathrm{mm}^{2}, 7.4 \pm 4.0 \mathrm{~N} / \mathrm{mm}^{2}$ and $399 \pm$ $130 \mathrm{mg} / \mathrm{cm}^{3}$ for Young's modulus, ultimate compression strength and mineral ash density of cancellous bone from healthy human femoral heads post mortem, respectively, were obtained by Rohlmann et al. [18]. Both the mechanical parameters and BMD of ashing represent higher values compared to our results (Table 4) and could depend on the fact that the investigation was done on healthy instead of osteoarthritic bone material as was used in our study. Our samples were prepared in a single orientation, so that the distribution of the Young's modulus was not due to anisotropy [4]. Bone is a complex material made of different organic and inorganic components; hence, the structural modulus $\left(E_{s}\right)$ describes the Young's modulus (mechanical properties) more accurately in conjunction with bone samples [23].

However, the correlation between properties as well as bone mineral density (Table 3 ) of retrieved bone samples and the bone density of the femoral head and neck previously measured in the same patients has not been investigated so far. Measurements of patient bone mineral density by DXA is a noninvasive technique and beneficial for determining fracture risk [20]. Au et al. [20] measured an average BMD of $758 \pm 114 \mathrm{mg} / \mathrm{cm}^{2}$ in the femoral neck of healthy female patients. In our study, a higher patient BMD of the neck $\left(1016 \pm 166 \mathrm{mg} / \mathrm{cm}^{2}\right)$ in osteoarthritic patients was found, as theoretically expected (Table 4). This may depend in part on the location of patients' DXA measurements at the femoral neck, in contrast to the in vitro measurements of the bone samples using the femoral head. This could also explain the low correlation coefficient between each patient's DXA BMD of the femoral neck and the mineral density of the bone sample as determined in vitro by DXA and ashing. On the other hand, each patient's DXA $\mathrm{BMD}$ of the femoral head demonstrated a significant linear correlation (Table 2). Therefore, a specific orientation for in vitro $\mathrm{BMD}$ measurements of bone samples is recommended in order to enable comparison to BMD calculations accomplished in vivo. In further studies, the presented results of osteoarthritic bone should be compared with bone samples from healthy individuals and osteoporotic patients of the same age.

In summary, a strong relationship was found between the mechanical properties and BMDs of retrieved cancellous samples from the femoral head and the BMDs of the respective patients measured in vivo. However, adequate orientation of both in vitro and in vivo DXA measurements at the proximal femur is required. The linear correlations found 
between mechanical data and bone mineral densities can help to determine the mechanical load capacity of individual patients in terms of surgical treatments by means of noninvasive bone density measurements preoperatively. In turn, this knowledge of mechanical properties could be useful for patient treatment, for example, in total joint arthroplasty, by choosing an adequate endoprosthetic implant adapted to the quality of the individual bone stock. Additional DXA measurements of the femoral head could derive useful data on the BMD for adequate fixation of implants like dynamic hip screws within the femoral head.

\section{Disclosure}

The authors state that there is no conflict of interests for any of the authors. No benefits in any form have been received or will be received from a commercial party related directly or indirectly to the subject of this paper.

\section{Authors' Contribution}

Y. Haba and R. Skripitz are contributed equally to this work.

\section{Acknowledgment}

The authors would like to thank the German Research Foundation (DFG) for supporting the study within the Graduate School GRK 1505/1 Welisa.

\section{References}

[1] W. D. Leslie and L. M. Lix, "Absolute fracture risk assessment using lumbar spine and femoral neck bone density measurements: derivation and validation of a hybrid system," Journal of Bone and Mineral Research, vol. 26, no. 3, pp. 460-467, 2011.

[2] E. Donnelly, "Methods for assessing bone quality: a review," Clinical Orthopaedics and Related Research, vol. 469, no. 8, pp. 2128-2138, 2011.

[3] T. M. Keaveny, P. F. Hoffmann, M. Singh et al., "Femoral bone strength and its relation to cortical and trabecular changes after treatment with PTH, alendronate, and their combination as assessed by finite element analysis of quantitative CT scans," Journal of Bone and Mineral Research, vol. 23, no. 12, pp. 19741982, 2008.

[4] C. M. Schoenfeld, E. P. Lautenschlager, and P. R. Jr. Meyer, "Mechanical properties of human cancellous bone in the femoral head," Medical and Biological Engineering, vol. 12, no. 3, pp. 313-317, 1974.

[5] C. M. Bagi, N. Hanson, C. Andresen et al., "The use of microCT to evaluate cortical bone geometry and strength in nude rats: correlation with mechanical testing, pQCT and DXA," Bone, vol. 38, no. 1, pp. 136-144, 2006.

[6] L. Mosekilde, S. M. Bentzen, G. Ortoft, and J. Jorgensen, “The predictive value of quantitative computed tomography for vertebral body compressive strength and ash density," Bone, vol. 10, no. 6, pp. 465-470, 1989.

[7] J. Lee, H. I. Shin, and S. Y. Kim, "Fractional quantitative computed tomography for bone mineral density evaluation: accuracy, precision, and comparison to quantitative computed tomography," Journal of Computer Assisted Tomography, vol. 28, no. 4, pp. 566-571, 2004.

[8] M. L. Bouxsein, D. A. Michaeli, D. B. Plass, D. A. Schick, and M. E. Melton, "Precision and accuracy of computed digital absorptiometry for assessment of bone density of the hand," Osteoporosis International, vol. 7, no. 5, pp. 444-449, 1997.

[9] C. Öhman, M. Baleani, E. Perilli et al., "Mechanical testing of cancellous bone from the femoral head: experimental errors due to off-axis measurements," Journal of Biomechanics, vol. 40, no. 11, pp. 2426-2433, 2007.

[10] E. Steinhauser, P. Diehl, M. Hadaller et al., "Biomechanical investigation of the effect of high hydrostatic pressure treatment on the mechanical properties of human bone," Journal of Biomedical Materials Research Part B, vol. 76, no. 1, pp. 130$135,2006$.

[11] J. Sierpowska, M. A. Hakulinen, J. Töyräs et al., "Prediction of mechanical properties of human trabecular bone by electrical measurements," Physiological Measurement, vol. 26, no. 2, pp. S119-S131, 2005.

[12] E. N. Ebbesen, J. S. Thomsen, H. Beck-Nielsen, H. J. NepperRasmussen, and L. Mosekilde, "Lumbar vertebral body compressive strength evaluated by dual-energy X-ray absorptiometry, quantitative computed tomography, and ashing," Bone, vol. 25, no. 6, pp. 713-724, 1999.

[13] N. L. Fazzalari, M. R. Forwood, K. Smith, B. A. Manthey, and P. Herreen, "Assessment of cancellous bone quality in severe osteoarthrosis: bone mineral density, mechanics, and microdamage," Bone, vol. 22, no. 4, pp. 381-388, 1998.

[14] H. P. Matter, T. v. Garrel, U. Bilderbeek, and W. Mittelmeier, "Biomechanical examinations of cancellous bone concerning the influence of duration and temperature of cryopreservation," Journal of Biomedical Materials Research, vol. 55, no. 1, pp. 40-44, 2001.

[15] DIN 50106 Testing of Metallic Materials Compression Test, 1978.

[16] C. Becker, A. W. Baltzer, M. Schneppenheim et al., "Experimentelle Validierung einer DXA- und MRT-basierten Knochendichtemessung durch Veraschung," Zentralblatt für Chirurgie, vol. 126, no. 5, pp. 402-406, 2001.

[17] B. Li and R. M. Aspden, "Composition and mechanical properties of cancellous bone from the femoral head of patients with osteoporosis or osteoarthritis," Journal of Bone and Mineral Research, vol. 12, no. 4, pp. 641-651, 1997.

[18] A. Rohlmann, H. Zilch, G. Bergmann, and R. Kolbel, "Material properties of femoral cancellous bone in axial loading-I: time-independent properties," Archives of Orthopaedic and Traumatic Surgery, vol. 97, no. 2, pp. 95-102, 1980.

[19] T. Uchiyama, T. Tanizawa, H. Muramatsu, N. Endo, H. E. Takahashi, and T. Hara, "Three-dimensional microstructural analysis of human trabecular bone in relation to its mechanical properties," Bone, vol. 25, no. 4, pp. 487-491, 1999.

[20] S. K. Au, W. Y. Choy, K. M. Chan et al., "Correlation of bone mineral density measured by peripheral quantitative computed tomography (pQCT) and dual x-ray absorptiometry (DEXA)," in Proceedings of the 20th Annual International Conference of the IEEE, Engineering in Medicine and Biology Society, vol. 2, pp. 629-631, IEEE Engineering in Medicine and Biology Society, 1998.

[21] A. Mazurkiewicz and T. Topoliński, "Relationships between structure, density and strength of human trabecular bone," Acta of Bioengineering and Biomechanics, vol. 11, no. 4, pp. 5561, 2009. 
[22] D. D. Cody, G. J. Gross, F. J. Hou, H. J. Spencer, S. A. Goldstein, and D. P. Fyhrie, "Femoral strength is better predicted by finite element models than QCT and DXA," Journal of Biomechanics, vol. 32, no. 10, pp. 1013-1020, 1999.

[23] C. Y. Ko, T. W. Lee, D. G. Woo, H. S. Kim, and B. Y. Lee, "Improved non-invasive biomechanical evaluation method for the virtue of risedronate," Key Engineering Materials, vol. 342-343, pp. 921-924, 2007. 


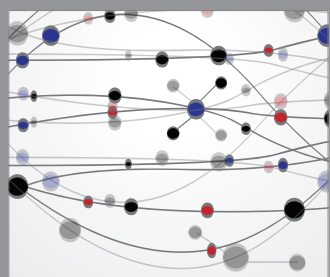

The Scientific World Journal
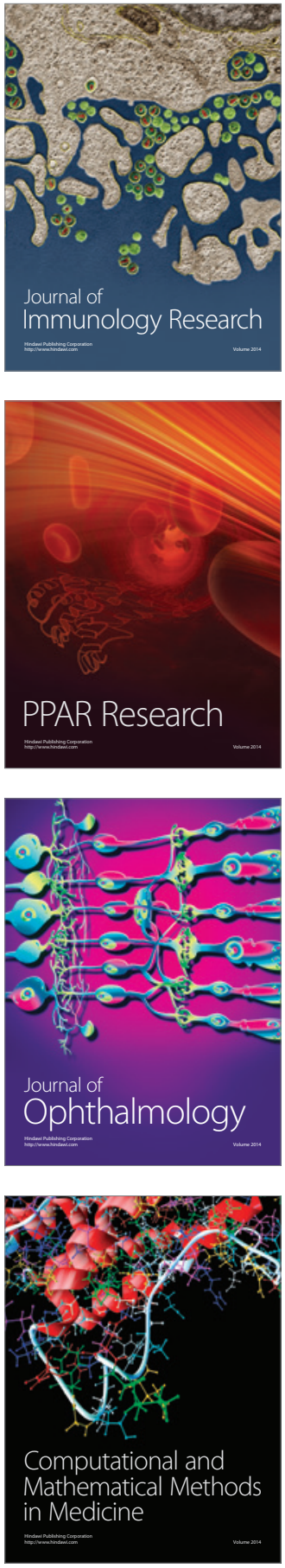

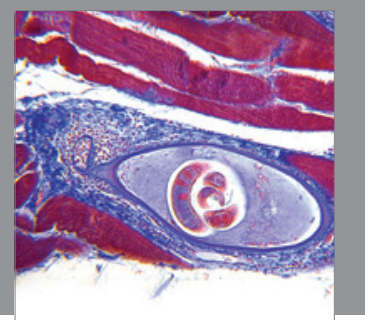

Gastroenterology

Research and Practice
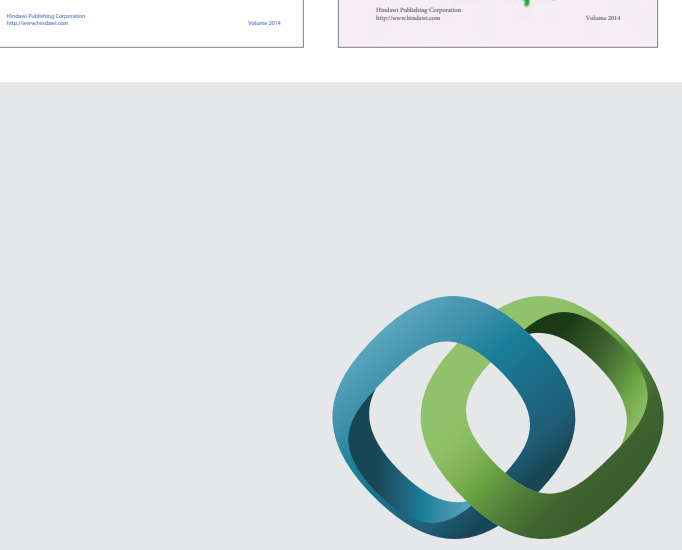

\section{Hindawi}

Submit your manuscripts at

http://www.hindawi.com
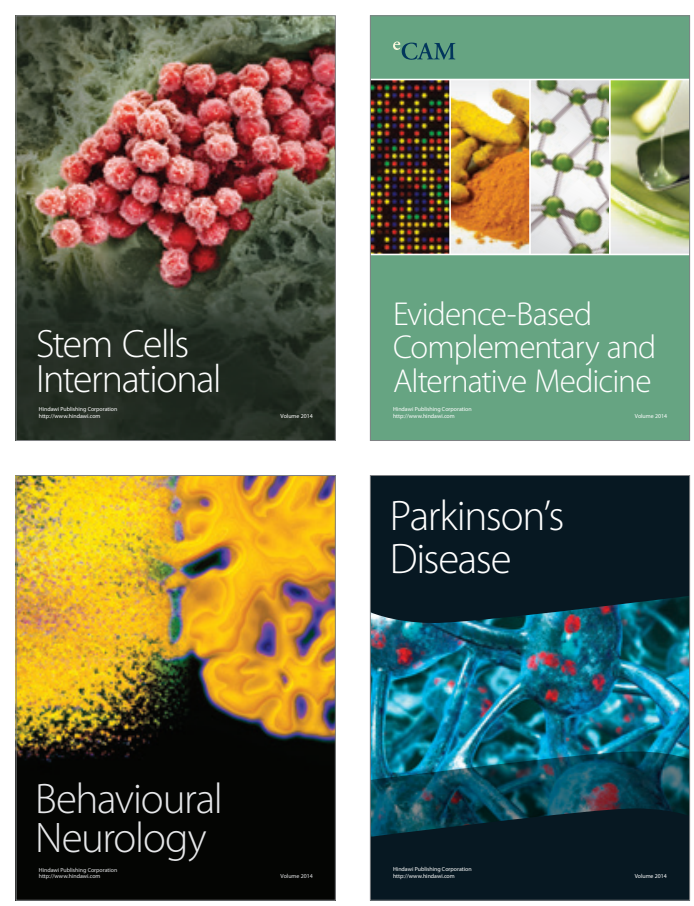

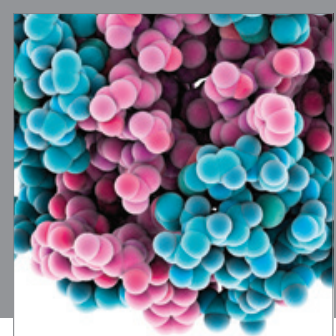

Journal of
Diabetes Research

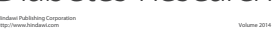

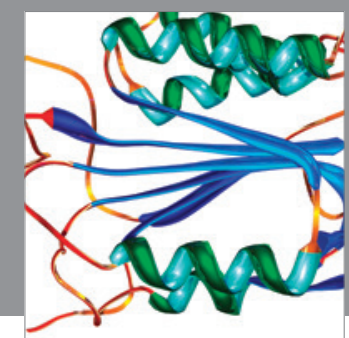

Disease Markers
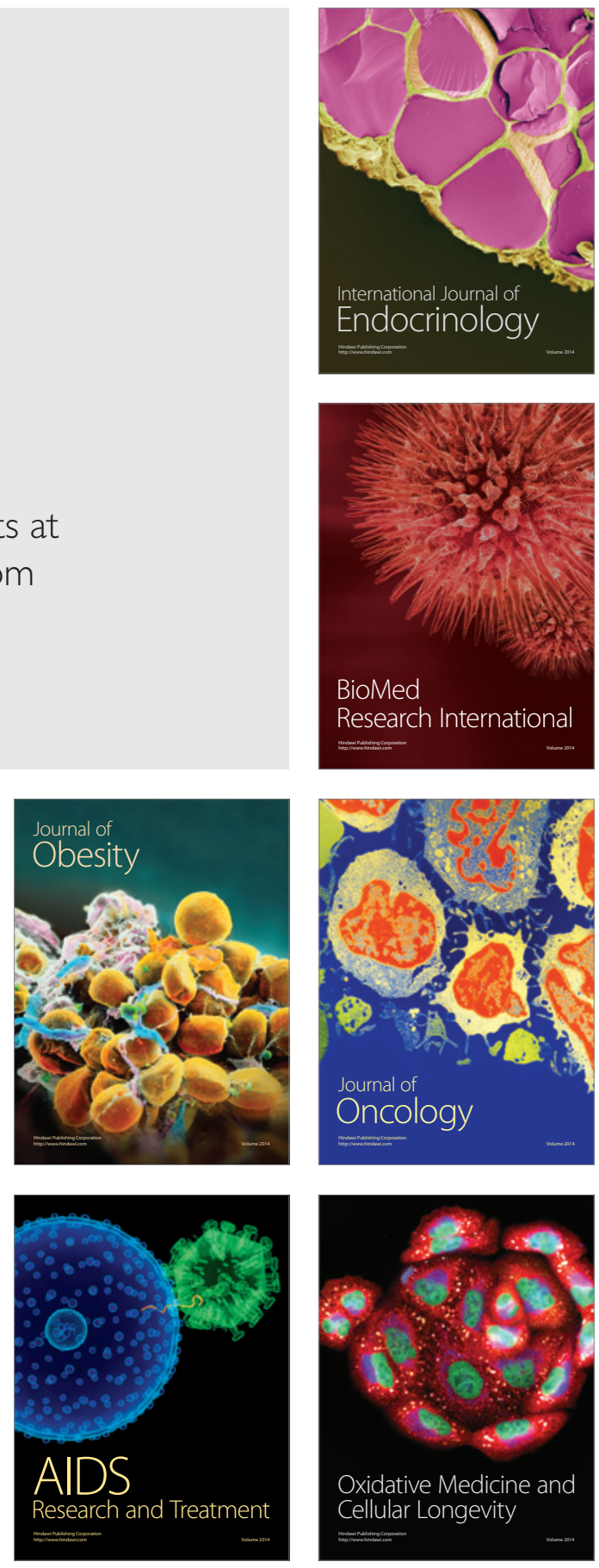